\title{
Segment 10 based molecular epidemiology of bluetongue virus (BTV) isolates from Turkey: 1999-2001
}

\author{
Aykut Ozkul a, ${ }^{\mathrm{a}}$, Arife Erturk ${ }^{\mathrm{b}}$, Elvin Caliskan ${ }^{\mathrm{b}}$, Fahriye Sarac $^{\mathrm{a}}$, Cagatay Ceylan ${ }^{\mathrm{c}}$, Peter Mertens ${ }^{\mathrm{d}}$, \\ Ozden Kabakli ${ }^{\text {b }}$, Ender Dincer ${ }^{\mathrm{e}}$, Sirin G. Cizmeci ${ }^{\mathrm{b}}$ \\ a Ankara University, Faculty of Veterinary Medicine, Virology Department, 06110 Ankara, Turkey \\ ${ }^{\mathrm{b}}$ Ministry of Agriculture and Rural Affairs, Central Veterinary Control and Research Institute, 06010 Ankara, Turkey \\ c Izmir Institute of Technology, Food Engineering Department, 35430 Izmir, Turkey \\ d Institute for Animal Health, Pirbright, Surrey GU240NF, England, UK \\ e Ankara University, Biotechnology Institute, 06500 Ankara, Turkey
}

\section{A R T I C L E I N F O}

\section{Article history:}

Received 29 September 2008

Received in revised form 4 February 2009

Accepted 5 February 2009

Available online 21 February 2009

\section{Keywords:}

Bluetongue

NS3/3A

Phylogenetic analysis

Turkey

\begin{abstract}
A B S T R A C T
Bluetongue is a significant arbovirus infection that has a negative impact on ruminant productivity in Turkey. Twenty-one Turkish BTV isolates were analyzed phylogenetically, based on genome segment 10 (Seg-10) nucleotide sequences. These analyses were used to explore the epidemiological background of individual isolates from both a regional and global perspective. In the regional analysis, the different BTV strains fell into two groups (Group 1 and Group 2). The Turkish virus isolates were localized in Group 1 which contains two sub-groups. The neighbor-joining analysis revealed that Seg-10 of majority of the Turkish viruses was closely related to certain other virus strains allocated in the eastern lineage. The Seg10 's of two viruses (TR25 and TR26) were more closely related to strains isolated in the Asia-Australia region. These strains belong to the 'eastern' topotype identified by [Maan, S., Maan, N.S., Ross-Smith, N., Batten, C.A., Shaw, A.E., Anthony, S.J., Samuel, A.R., Darpel, K.E., Veronesi, E., Oura, C.A.L., Singh,K.P., Nomikou, K., Potgieter, A.C., Attoui, H., van Rooij, E., van Rijn, P., De Clercq, K., Vandenbussche, F., Zientara, S., Bréard, E., Sailleau, C., Beer, M., Hoffman, B., Mellor, P.S., Mertens, P.P.C., 2008. Sequence analysis of bluetongue virus serotype 8 from the Netherlands 2006 and comparison to other European strains. Virology 377, 308-318]. Comparisons of amino acid sequences deduced from the Seg-10 genes showed a high level of conservation in the NS3/3A proteins from the Turkish viruses. The more frequent amino acid substitutions were identified by multiple alignment analysis, and one of the isolates (TR23) was remarkably found to be genetically quite distinct from the other isolates.
\end{abstract}

(C) 2009 Elsevier B.V. All rights reserved.

\section{Introduction}

Bluetongue (BT) is an arthropod-transmitted disease of wild and domestic ruminants caused by bluetongue virus (BTV), a member of the genus Orbivirus family Reoviridae (Mertens et al., 2005). Sheep and some species of deer frequently become clinically ill as a result of BTV infection. The disease can cause up to $100 \%$ morbidity in sheep with 0-50\% case fatality rates (Schwartz-Cornil et al., 2008). Goats, cattle and wild ruminants generally remain asymptomatic, although the northern European strain of BTV-8 has also caused a low but significant level of clinical signs and mortality $(<1 \%)$ in cattle (Brewer and MacLachlan, 1994; Jessup, 1985; Koumbati et

* Corresponding author at: Ankara University, Faculty of Veterinary Medicine, Virology Department, Irfan Bastug Cad., Diskapi, 06110 Ankara, Turkey. Tel.: +90 312317 0315x364; fax: +90 3123173348 .

E-mail address: ozkul@veterinary.ankara.edu.tr(A. Ozkul). al., 1999; Maan et al., 2007; Szmaragd et al., 2007). BT can spread rapidly under suitable conditions, threatening international trade in livestock and their products. The disease is therefore regarded as economically important and is included in the 'list' of diseases compiled by the Office International des Epizooties (Alexander et al., 1994).

BTV infection was observed in temperate and tropical countries between the latitudes of $40^{\circ} \mathrm{S}$ and $53^{\circ} \mathrm{N}$, including several countries from the Americas, Africa, Asia and Australia, where competent vector midges of the Culicoides species are present. However, at least eight different BTV serotypes have been invading Europe (types 1, 2, 4, 8, 9, 16) since 1998 (Schwartz-Cornil et al., 2008). During 2006 , an outbreak of BT was identified for the first time in northern European countries, caused by BTV-8, raising concerns about its origins and epidemiology (Darpel et al., 2007). The distribution and prevalence of different BTV serotypes varies between each endemic area (see: http://www.reoviridae.org/dsRNA_virus_proteins/btvserotype-distribution.htm). 


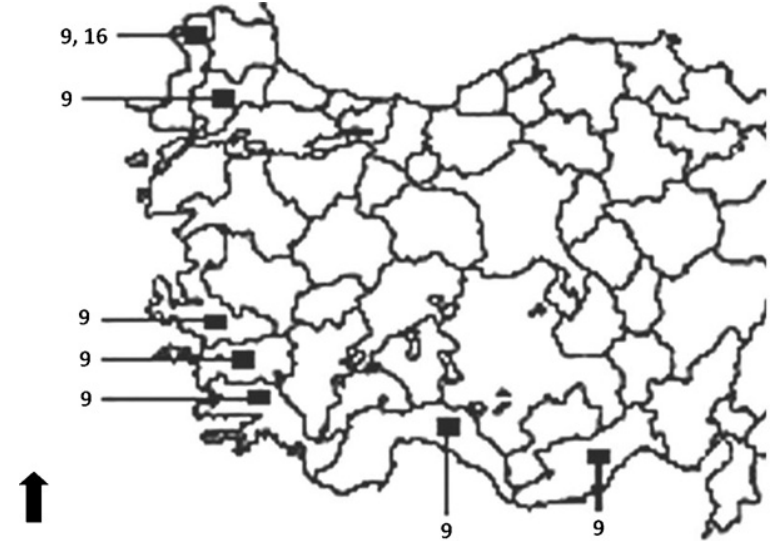

Fig. 1. The geographical distribution (on a provincial scale) of the Turkish BTV isolates involved in this study. Figure shows western part of Turkey and arrow indicates north.

BTV outbreaks have occurred annually in the Mediterranean Basin since 1998, resulting in significant economic losses (Mellor and Wittmann, 2002). During the last decade five different serotypes of BTV have been detected circulating in the Mediterranean basin (BTV-1, 2, 4, 9, 16). BTV-15 has also been detected in Israel, but does not appear to have spread to adjacent countries. Additional but distinct strains of BTV-1 and 4 were also detected in the western Mediterranean region (Breard et al., 2007).

A global evaluation, based on sequence analysis of genome segment 10 (Seg-10) from 137 strains isolated in different regions of the world, identified two principal groups irrespective of their serotype or year of isolation. All of the viruses from Asia and Australia were grouped in one clade, whereas those from other regions were present in both clades (Balasuriya et al., 2008).

The study described here examines the strains of different BTV serotypes that were circulating in western parts of Turkey between 1999 and 2001, using RT-PCR methods and nucleotide analysis of their Seg-10 sequences to elucidate the molecular evolution of BTV in the region. This study was also designed to add one more link to the chain of knowledge concerning virus epidemiology in the eastern Mediterranean Basin.

\section{Materials and methods}

\subsection{Virus isolation and serotyping}

A total of 21 BTV isolates were used in the study. Samples from the suspect cases of BT were received from 7 provinces, two of which were from European Turkey (Thrace), while the rest were from western and southwestern Turkey (Fig. 1). Nineteen viruses were isolated in the virology laboratory of the Central Veterinary
Research and Control Institute, Ankara, from blood and organ samples obtained from sick and/or dead animals, while the remaining two (TR-25 and TR-26) were detected by RT-PCR in aborted bovine fetuses at the laboratory of Virology Department, Ankara University. Sample homogenates were inoculated into the yolk sac of embryonated chicken eggs, followed by blind passage in BHK-21 cell monolayers. Culture fluids from all cultures showing positive cytopathic effects were tested by antigen capture-ELISA (Virology Laboratory, EMAI, Camden NSW, Australia) for initial identification of BTV and were subsequently stored at $-80^{\circ} \mathrm{C}$ for future applications. Serotyping of the BTV isolates was performed using RT-PCR based on segment 2 sequence differences, as described previously (Mertens et al., 2007). A list of the isolates and further details regarding the original sampling locations of the isolates are given in Table 1 and Fig. 1.

\subsection{RNA extraction, RT-PCR and sequencing}

Viral RNA was extracted after repeated cycles of freezing and thawing, from $200 \mu \mathrm{l}$ of cell-culture supernatant from BTV infected Vero cells using 'spin columns' from a "Viral RNA extraction kit" (Roche, Germany), as described in the manual. Samples were prepared in duplicate and the RNAs eluted in RNase-free water. RNA concentration was measured using a NanoDrop ${ }^{\circledR}$ ND-1000 Spectrophotometer then immediately used for cDNA synthesis. Reverse transcription (RT) was performed using "RevertAid kit" protocol based on random hexamer priming (Fermentas, Lithuania) according to the manufacturer's instructions. PCR primers (Forward: 5'-gttaaaaagtgtcgctgccatg-3' and Reverse: 5'gtaagtgtgtagcgccgcataccct-3') for Seg-10 amplification were used as described by Nikolakaki et al. (2005). The PCR was initiated by a single denaturation step at $96^{\circ} \mathrm{C}$ for $10 \mathrm{~min}$, followed by 40 cycles of $1 \mathrm{~min}$ at $58^{\circ} \mathrm{C}, 1 \mathrm{~min}$ at $72^{\circ} \mathrm{C}$ and $1 \mathrm{~min}$ at $94^{\circ} \mathrm{C}$. The mixture was then incubated, as a single step, for $1 \mathrm{~min}$ at $50^{\circ} \mathrm{C}$ and $10 \mathrm{~min}$ at $72^{\circ} \mathrm{C}$ for final extension. Five microliters of each PCR product was analyzed in $1 \%$ agarose (Prona, Spain) gels containing ethidium bromide (Sigma, USA).

The final DNA products were purified by gel extraction and cloned into pTZ57R TA cloning plasmid (Fermentas, Lithuania). Plasmid DNAs were sequenced directly in a CEQ 8000 genetic analyzer (Beckmann Coulter, USA) using the dye termination cycle sequencing kit in the Virology department's laboratory, at Ankara University. The Seg-10 sequences from the Turkish BTV isolates have been submitted to GenBank. The assigned accession numbers are presented in Table 1.

\subsection{Phylogenetic analysis}

Segment 10 sequences coding for NS3/NS3A were aligned with those downloaded from GenBank. The evolutionary history of the Turkish isolates, based on regional sequence comparisons

Table 1

Serotype identification of BTV isolates and their assigned GenBank accession numbers.

\begin{tabular}{|c|c|c|c|c|c|c|c|}
\hline Isolate code & Isolation year & Serotype & GenBank accession \# & Isolate code & Isolation year & Serotype & GenBank accession \# \\
\hline TR1 & 1999 & 9 & EF554838 & TR12 & 2000 & 9 & EF554849 \\
\hline TR2 & 1999 & 9 & EF554839 & TR18 & 1999 & 9 & EF554850 \\
\hline TR3 & 1999 & 9 & EF554840 & TR19 & 1999 & 16 & EF554851 \\
\hline TR4 & 1999 & 9 & EF554841 & TR20 & 1999 & 9 & EF554852 \\
\hline TR5 & 2000 & 9 & EF554842 & TR21 & 2000 & 9 & EF554853 \\
\hline TR6 & 1999 & 9 & EF554843 & TR22 & 1999 & 9 & EF554854 \\
\hline TR7 & 1999 & 9 & EF554844 & TR23 & 2001 & ND & EF554855 \\
\hline TR8 & 1999 & 9 & EF554845 & TR24 & 2001 & 9 & EF554856 \\
\hline TR9 & 1999 & 9 & EF554846 & TR25 & 2001 & 9 & EF554857 \\
\hline TR10 & 2000 & 9 & EF554847 & TR26 & 2001 & 9 & EF554858 \\
\hline TR11 & 2000 & 9 & EF554848 & & & & \\
\hline
\end{tabular}

ND: not determined. 

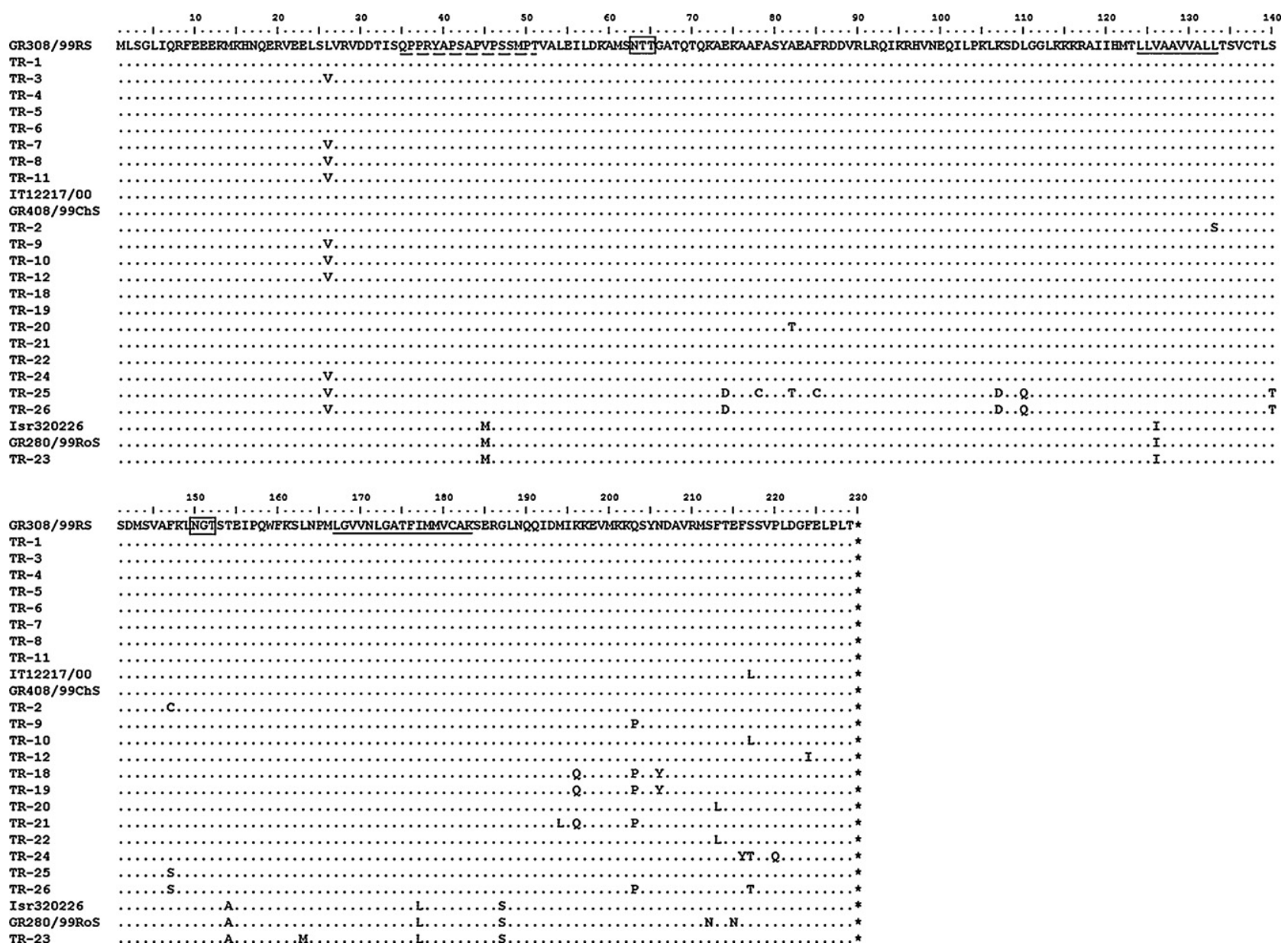

Fig. 2. Multiple alignment of the deduced NS3/NS3A amino acid sequences of BTV isolates analyzed in this study. Representatives of BTV-4 (e.g. GR280/99RoS, AY691691; Isr320226, AY775158), BTV-9 (e.g. GR408/99ChS, AY449651; IT12217/00, AY775161) and BTV-16 (e.g. GR308/99RS, AY449652) serotypes from nearby geographies are included to the alignment. Underlined areas indicate transmembrane domains. Dotted underline shows signal peptide sequence. Boxes indicate glycosylation sites.

was inferred using the neighbor-joining method (Saitou and Nei, 1987). An optimal tree was generated with a sum branch length $=0.76933444$. The percentage of replicate trees in which the associated taxa clustered together in the bootstrap test (1000 replicates) is shown next to the branches (Felsenstein, 1985). The tree is drawn to scale, with branch lengths in the same units as those of the evolutionary distances used to infer the phylogenetic tree. The evolutionary distances were computed using the maximum composite likelihood method (Tamura et al., 2004) and are reflected as the units of the number of nucleotide substitutions per site. All positions containing gaps and missing data were eliminated from the dataset (complete deletion option). Phylogenetic analyses were conducted in MEGA4 (Tamura et al., 2007).

\section{Results}

\subsection{Serotypic differentiation of the BTV isolates}

Nineteen of the Turkish isolates were identified by RT-PCR as BTV-9, while one of them were identified as BTV-16 (Table 1). However, one isolate (TR23) could not be identified using the current serotype specific primer panel, suggesting that it might belong to a different serotype.

\subsection{Amino acid variation among the field isolates}

Comparison of amino acid sequences, deduced from the Seg-10 nucleotide sequence, showed a high level of conservation in the
NS3/3A proteins of the Turkish isolates. Similarity indices of amino acid sequences of Turkish BTV isolates were observed as varying between $93.8 \%$ and $100 \%$. Overall the most frequent variation was seen in the 26th amino acid. 11 of the isolates have a Leucine (L), whereas the rest have a Valine $(\mathrm{V})$ in the same position. The second most frequent variation was seen at position 203, where five of the field samples have Proline (P), while the rest have Lysine (K). Fig. 2 shows that most of the variations were observed in the intracellular domains, especially in the second intracellular domain, while two of the glycosylation sites remained fully conserved. One of the most interesting observations is the relatively large number of unique amino acid differences that were detected in NS3 of isolate TR23. It contains Methionine (M) at positions 45 and 163, Isoleucine (I) at position 126, Arginine (A) at 154, Leucine (L) at 177 and Glycine (G) at 187 , when compared to the other strains. The accumulation of these mutations set this strain apart from the other Turkish strains analyzed and caused high similarity to Greek BTV-4 isolates (e.g. GR 280/99RoS; GenBank accession: AY691691).

\subsection{Phylogenetic analyses}

Sequence analyses of Seg-10 were used to determine the overall level of nucleotide variation within the NS3 genes, which can be used to identify their phylogenetic topotype and to help determine the origins of the virus strain itself (Bonneau et al., 1999). The phylogenetic analysis of Seg-10 was therefore carried out from both a regional and global perspective. In the regional analysis, two large groups were identified (Group 1 and Group 2). All of the 


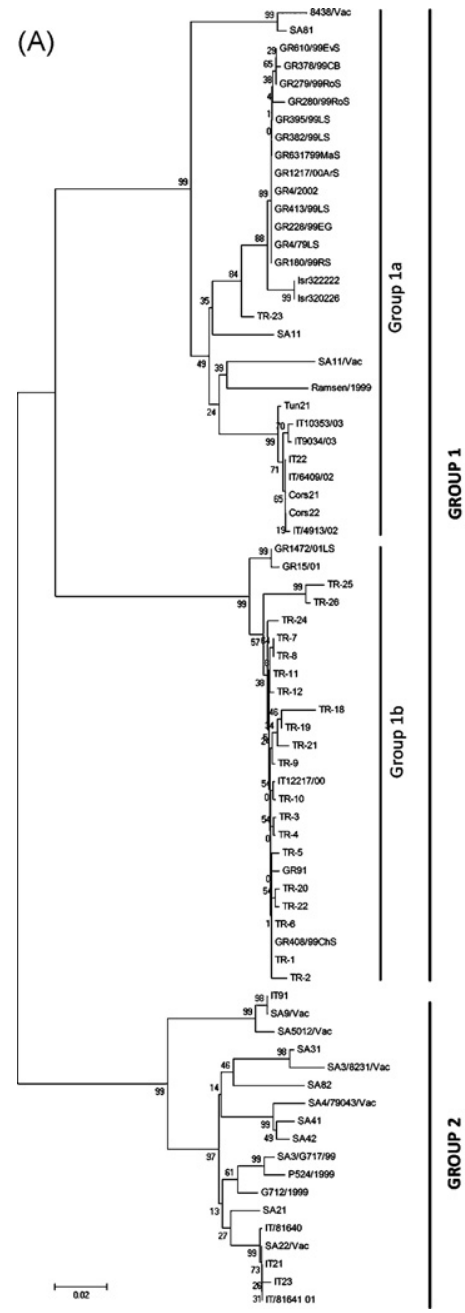

(B)

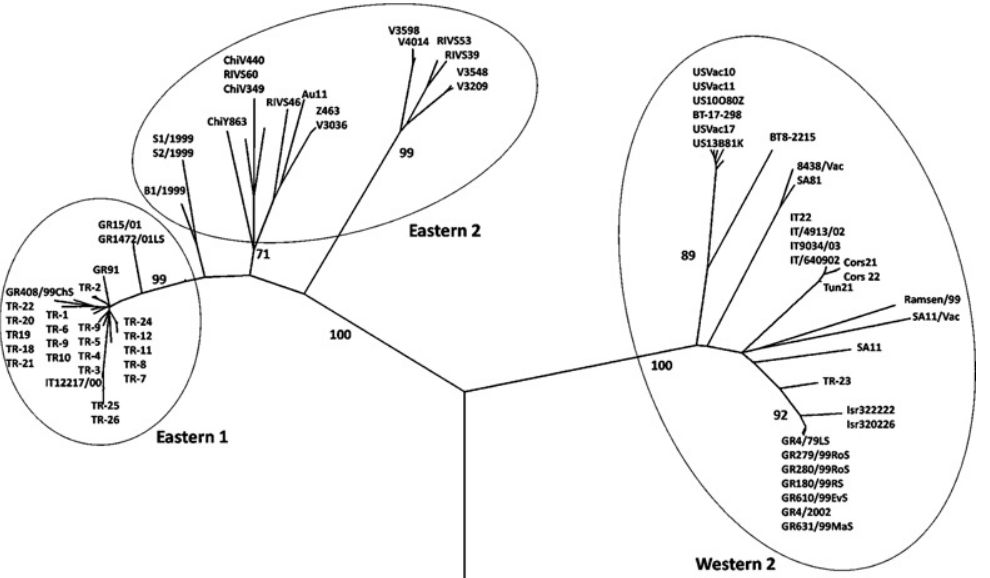

$\frac{2}{y^{2}}$

$\stackrel{\longmapsto}{0.01}$

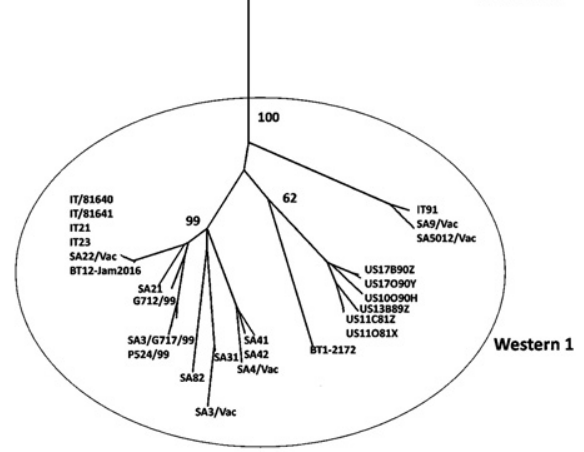

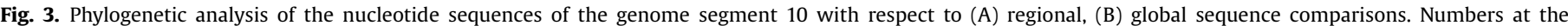

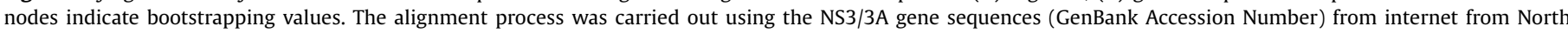

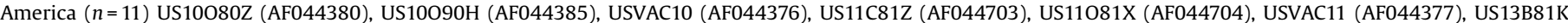

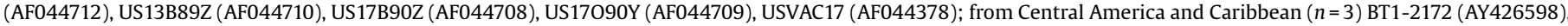

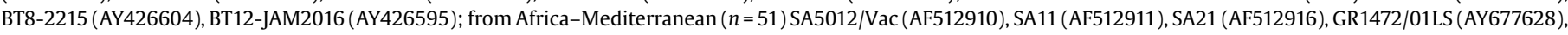

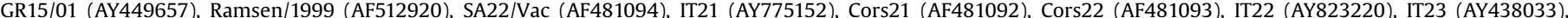

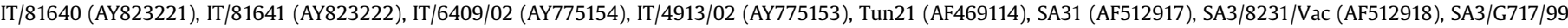

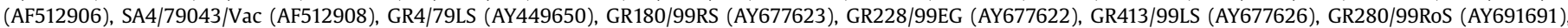

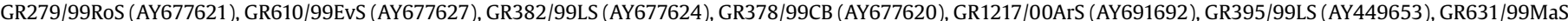

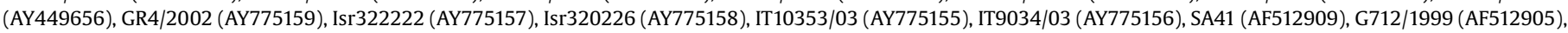

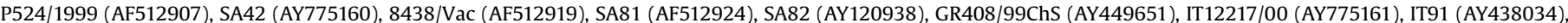

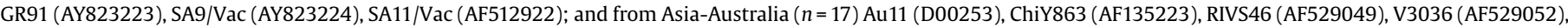

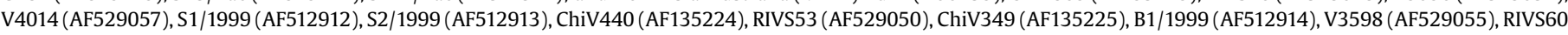
(AF529059), V3209 (AF529053), V3548 (AF529054), Z463 (AF529058), RIVS39 (AF529051), respectively.

Turkish isolates were localized in Group 1, which contained two sub-groups (Group 1a and Group 1b). The majority of the Turkish isolates clustered within Group 1b, which comprises viruses from 'eastern' lineage (Fig. 3A). On the other hand, one (TR23) of the Turkish strains clustered within Group $1 \mathrm{a}$ and closely related to thirteen Greek (Nikolakaki et al., 2005) and two Israeli BTV-4 isolates, which belong to 'western' lineage (Maan et al., 2007, 2008; Mertens et al., 2007). Strains TR25 and TR2 6 were isolated from the southern part of Turkey, some distance away from the rest of the isolates. The global analysis revealed that these strains (TR25 and TR26) were closely related to isolates from Asia-Australia (Fig. 3B). TR23 isolate is closely related Greek and Israeli BTV-4 isolates belonging to the "western 2" lineage (Fig. 3B). The global analysis showed similar topological diversity to that indicated in the previous studies (Balasuriya et al., 2008; Maan et al., 2008).

\section{Discussion}

This study was carried out to identify and analyze the BTV strains circulating in some parts of Turkey during the infamous 1998-2001 epidemics in that part of the Mediterranean region, using sequence alignments and phylogenetic analyses of genome segment 10 (the NS3/NS3A gene). These analyses confirmed that BTV strains from different locations form two phylogenetically different clades in both the global and regional analysis, with further subclades identified within each group, in a similar manner to the earlier studies including a study by MacLachlan et al. (2007), which used S10 nucleotide sequences from USA and French Marthinique Island to indentify two major clades/clusters (Balasuriya et al., 2008; Pierce et al., 1998; van Niekerk et al., 2003). Our results also support this differentiation. Different serotypes of BTV can distribute within 
both clusters. This could indicate independent evolution of segment 2 and segment 10 and the exchange of genome segments between different virus strains by reassortment.

The majority of the Turkish field BTV isolates fall into the same phylogenetic group as the Greek isolates (Nikolakaki et al., 2005), indicating the possible spread of virus between these two neighboring regions. Strains TR25 and TR26 appeared to be grouped differently in the phylogenetic analysis from the majority of the strains with a closer relationship to Greek isolates of BTV-1, indicating a difference in their origin. These two strains were isolated from geographically different regions (southern Turkey) and are genetically different from the other viruses. These results indicate that in addition to earlier reports of the regional distribution of BTV serotypes 1, 4, 9, and 16 in the eastern Mediterranean Basin, there may be differences in the local distribution of certain strains or serotypes within this region (Saegerman et al., 2008). On the other hand, the serotypically unidentified TR23 isolate is closely related Greek and Israeli BTV-4 isolates. All these viruses belong to the "western 2" lineage according to Maan et al. (2008) and thus, may indicate that unless there was a reassortment event, TR23 could belong to a cluster of BTV-4 isolates that circulate in the eastern Mediterranean region (Breard et al., 2007). In addition, global analysis performed in our study based on sequences of genome segment 10 (Seg-10) from 137 BTV strains isolated in different regions of the world, revealed two principal topotypic groups (eastern and western) irrespective of their serotype or year of isolation as identified very recently (Maan et al., 2008).

In their study, Balasuriya et al. (2008) suggested that the introduction of live-attenuated vaccines for BTV-3, 8, 9, 10 and 11 serotypes in Turkey was the trigger for the epizootics seen in the Mediterranean region between 1998 and 2001. However, to date, no live-attenuated BTV vaccines for these serotypes have been used in Turkey. Indeed the only live-attenuated BTV vaccine that has been used in Turkey was produced against serotype 4 by a laboratory of the Ministry of Agriculture and Rural Affairs. This vaccine strain of BTV-4 shows a significant level of variation in genome segment 2 , when compared to all of the field strains of BTV-4 isolated the Mediterranean region since 1998 . These strains are more closely related to BTV-4 from Cyprus, which have been isolated periodically since the 1960s (Mellor, 1990). These data indicate that the vaccination programme in Turkey did not cause any of the subsequent European BTV outbreaks between 1998 and 2008.

The presence of the virus in the Mediterranean Basin and in Middle-Central Asia regions has been documented previously (Saegerman et al., 2008). The presence of BTV has also been reported in the Mediterranean region several times from 1943 onwards. Epizootics were reported in Cyprus (1943), Israel (1950s), the Iberian Peninsula (1956), Cyprus (1977), the Greek island of Lesbos (1979) and Turkey (1994). These epizootics did not persist and involved only a single BTV serotype on each occasion (Gerbier et al., 2008). BTV-9 was detected in the eastern Mediterranean region in October 1998 and has been circulating in this area, including Turkey (1999) and other neighboring countries. In addition to BTV9, three other serotypes (BTV-1, 4 and 16) were also reported in some of these countries. Other BTV strains of BTV-1 and BTV-2, which appear to have originated from Sub-Saharan Africa, have also begun to circulate in the western Mediterranean region (Gerbier et al., 2008; Purse et al., 2006). Similarly, Nikolakaki et al. (2005) concluded that BTV genome segment 10 was derived from two separate lineages. They also compared NS3 sequences and found that the field isolates showed a high degree of similarity, indicating the same origin but vaccine and field isolates showed a significant divergence, also suggesting that the vaccine strain was not the source of the recent European epidemics.

It is known that the BTV quasi-species evolve independently of each other via a mechanism similar to genetic drift in host specific fashion. This process generates virus quasi-species populations in both ruminant and insect hosts. Since the main vector for BTV is thought to be adults of certain Culicoides species, they can acquire and amplify minor variants of the virus quasi-species, functioning like genetic sinks for less probably found quasi-species. Bonneau et al. (2002) reported that NS3/NS3A sequences from a single site in California had a considerable heterogeneity, which also indicates vector-dependent genome mutations. This corresponds to accumulation of single mutations in a population over time (genetic drift). It is also known that the changes in the Seg-10 sequences are very slow. The observed phylogenetic groups of Seg-10 may either be the result of single point mutations in the sequence, accrued over long time periods or more drastic changes such as reassortment of individual gene segments (genetic shift), which was also observed for several other reoviruses. The use of live-attenuated viruses as vaccines, poses certain disadvantages due to recombination between different BTV strains (Batten et al., 2008), potentially resulting in genetic reassortment which has been observed in other reoviruses (Liu et al., 2003). There is an on-going project in our laboratory to prepare an inactive vaccine for the BTV-4, 9 and 16 strains circulating in Turkey.

Most of the variations in the amino acid sequence were observed in the intracellular parts of the protein, especially in the neighborhood of C terminus. NS3 is a membrane protein with a role in the egress of the virus from infected cells (Hyatt et al., 1991). Other important features of NS3 include the two transmembrane domains which allow it to act as a viroporin, and extracellular portions known to form a loop that are thought to be important in terms of recognition by cells (Han and Harty, 2004). Almost no amino acid substitutions were observed in the extra-cellular and glycosylation sites of the NS3 proteins of isolated BT viruses.

\section{Conclusion}

BT infection in Turkey was caused by two BTV serotypes (types 9 and 16) between 1999 and 2001. The majority of these viruses were found to be closely related to those presented in neighboring European countries. Molecular epidemiologic evidence obtained by phylogenetic analysis of two southern isolates supports the hypothesis that virus incursions have entered Turkey from neighboring countries to the east. The Seg-10 nucleotide sequences could provide valuable data for attempts for topotypic analysis of the viruses in terms of their geographic origins. However an analysis of other genome segments should be performed to provide an overall picture of virus evolution from both local and global perspectives. In particular this would give evidence of genome segment exchange (reassortment) between different virus isolates.

\section{Acknowledgement}

The study was supported by a grant of The Scientific and Technological Research Council of Turkey (Project No.: 1050241).

\section{References}

Alexander, K.A., MacLachlan, N.J., Kat, P.W., House, C., O’Brien, S.J., Lerche, N.W., Sawyer, M., Frank, L.G., Holekamp, K., Smale, L., McNutt, W., Laurenson, M.K. Mills, M.G.L., Osburn, B.I., 1994. Evidence of natural bluetongue virus infection among African carnivores. Am. J. Trop. Med. Hyg. 51, 568-576.

Balasuriya, U.B.R., Nadler, S.A., Wilson, W.C., Pritchard, L.I., Smythe, A.B., Savini, G., Monaco, F., De Santis, P., Zhang, N., Tabachnick, W.J., MacLachlan, N.J., 2008. The NS3 proteins of global strains of bluetongue virus evolve into regional topotypes through negative (purifying) selection. Vet. Microbiol. 126, 91-100.

Batten, C.A., Maan, S., Shaw, A.E., Maan, N.S., Mertens, P.P.C., 2008. A European field strain of bluetongue virus derived from two parental vaccine strains by genome segment reassortment. Virus Res. 137, 56-63.

Bonneau, K.R., Zhang, N., Zhu, J., Zhang, F., Li, Z., Zhang, K., Xiao, L., Xiang, W., MacLachlan, N.J., 1999. Sequence comparison of the L2 and S10 genes of bluetongue 
viruses from the United States and the People's Republic of China. Virus Res. $61,153-160$

Bonneau, K.R., Topol, J.B., Gerry, A.C., Mullens, B.A., Velten, R.K., MacLachlan, N.J., 2002. Variation in the NS3/NS3A gene of bluetongue viruses contained in Culicoides sonorensis collected from a single site in southern California. Virus Res. 84, 59-65.

Breard, E., Sailleau, C., Nomikou, K., Hamblin, C., Mertens, P.P., Mellor, P.S., El Harrak, M., Zientara, S., 2007. Molecular epidemiology of bluetongue virus serotype 4 isolated in Mediterranean basin between 1979 and 2004. Virus Res. 125, 191-197.

Brewer, A.W., MacLachlan, N.J., 1994. The pathogenesis of bluetongue virus infection of bovine blood cells in vitro: ultrastructural characterization. Arch. Virol. 136, 287-298.

Darpel, K.E., Batten, C.A., Veronesi, E., Shaw, A.E., Anthony, S., Bachanek-Bankowska, K., Kgosana, L., bin-Tarif, A., Carpenter, S., Müller-Doblies, U.U., Takamatsu, H.H., Mellor, P.S., Mertens, P.P., Oura, C.A., 2007. Clinical signs and pathology shown by British sheep and cattle infected with bluetongue virus serotype 8 derived from the 2006 outbreak in northern Europe. Vet. Rec. 161, 253-261.

Felsenstein, J., 1985. Confidence limits on phylogenies: an approach using the bootstrap. Evolution 39, 783-791.

Gerbier, G., Biteau-Coroller, F., Grillet, C., Parodi, J., Zientera, S., Baldet, T., Guis, H., Roger, F., 2008. Description of the outbrek of bluetongue in Corsica in 2003, and lessons for surveillance. Vet. Rec. 162, 173-176.

Han, Z., Harty, R.N., 2004. The NS3 protein of bluetongue virus exhibits Viroporin-like properties. J. Biol. Chem. 279, 43092-43097.

Hyatt, A.D., Gould, A.R., Coupar, B., Eaton, B.T., 1991. Localization of the non-structura protein NS3 in bluetongue virus-infected cells. J. Gen. Virol. 72, 2263-2267.

Jessup, D.A., 1985. Epidemiology of two orbiviruses in California's native wild ruminants: preliminary report. Prog. Clin. Biol. Res. 178, 53-65.

Koumbati, M., Mangana, O., Nomikou, K., Mellor, P.S., Papadopoulos, O., 1999. Duration of bluetongue viraemia and serological responses in experimentally infected European breeds of sheep and goats. Vet. Microbiol. 64, 277-285.

Liu, H., Lee, L.H., Hsu, H.W., Kuo, L.C., Liao, M.H., 2003. Molecular evolution of avian reovirus: evidence for genetic diversity and reassortment of the S-class genome segments and multiple cocirculating lineages. Virology 314, 336-349.

Maan, S., Maan, N.S., Samuel, A.R., Rao, S., Attoui, H., Mertens, P.P.C., 2007. Analysis and phylogenetic comparisons of full-length VP2 genes of the twenty-four bluetongue virus serotypes. J. Gen. Virol. 88, 621-630.

Maan, S., Maan, N.S., Ross-Smith, N., Batten, C.A., Shaw, A.E., Anthony, S.J., Samuel, A.R., Darpel, K.E., Veronesi, E., Oura, C.A.L., Singh, K.P., Nomikou, K., Potgieter, A.C., Attoui, H., van Rooij, E., van Rijn, P., De Clercq, K., Vandenbussche, F., Zientara, S., Bréard, E., Sailleau, C., Beer, M., Hoffman, B., Mellor, P.S., Mertens, P.P.C., 2008. Sequence analysis of bluetongue virus serotype 8 from the Netherlands 2006 and comparison to other European strains. Virology 377, 308-318.
MacLachlan, N.J., Zientara, S., Stallknecht, D.E., Boone, J.D., Goekjian, V.H., Sailleau, C., Balasuriya, U.B., 2007. Phylogenetic comparison of the S10 genes of recent isolates of bluetongue virus from the United States and French Martinique Island. Virus Res. 129, 236-240.

Mellor, P.S., 1990. The replication of bluetongue virus in Culicoides vectors. Curr. Top. Microbiol. Immunol. 162, 143-161.

Mellor, P.S., Wittmann, E.J., 2002. Bluetongue virus in the Mediterranean Basin 1998-2001. Vet. J. 164, 20-37.

Mertens, P.P.C., Maan, S., Samuel, A., Attoui, H., 2005. Orbivirus, Reoviridae. In: Fauquet, C.M., Mayo, M.A., Maniloff, J., Desselberger, U., Ball, L.A. (Eds.), Virus Taxonomy, VIIIth Report of the ICTV. Elsevier/Academic Press, London, pp. 466-483.

Mertens, P.P., Maan, N.S., Prasad, G., Samuel, A.R., Shaw, A.E., Potgieter, A.C., Anthony, S.J., Maan, S., 2007. Design of primers and use of RT-PCR assays for typing European bluetongue virus isolates: differentiation of field and vaccine strains. J. Gen. Virol. 88, 2811-2823.

Nikolakaki, S.V., Nomikou, K., Koumbati, M., Mangana, O., Papanastassopoulou, M., Mertens, P.P., Papadopoulos, O., 2005. Molecular analysis of the NS3/NS3A gene of Bluetongue virus isolates from the 1979 and 1998-2001 epizootics in Greece and their segregation into two distinct groups. Virus Res. 114, 6-14

Pierce, C.M., Balasuriya, U.B., MacLachlan, N.J., 1998. Phylogenetic analysis of the S10 gene of field and laboratory strains of bluetongue virus from the United States. Virus Res. 55, 15-27.

Purse, B.V., Mellor, P.S., Rogers, D.J., Samuel, A.R., Mertens, P.P., Baylis, M., 2006 Climate change and the recent emergence of bluetongue in Europe. Nat Rev Microbiol. 4, 160.

Saegerman, C., Berkvens, D., Mellor, P.S., 2008. Bluetongue epidemiology in the European Union. Emerg. Infect. Dis. 14, 539-544.

Saitou, N., Nei, M., 1987. The neighbor-joining method: a new method for reconstruction phylogenetic trees. Mol. Biol. Evol. 4, 406-425.

Schwartz-Cornil, I., Mertens, P.P.C., Contreras, V., Hemati, B., Pascale, F., Breard, E., Mellor, P.S., MacLachlan, N.J., Zientera, S., 2008. Bluetongue virus: virology, pathogenesis and immunity. Vet. Res. 39 (46), doi:10.1051/vetres:2008023.

Szmaragd, C., Wilson, A., Carpenter, S., Mertens, P.P., Mellor, P.S., Gubbins, S., 2007. Mortality and case fatality during the recurrence of BTV-8 in northern Europe in 2007. Vet. Rec. 161, 571-572.

Tamura, K., Dudley, J., Nei, M., Kumar, S., 2007. MEGA4: molecular evolutionary genetics analysis (MEGA) software version 4.0. Mol. Biol. Evol. 24, 1596-1599.

Tamura, K., Nei, M., Kumar, S., 2004. Prospects for inferring very large phylogenies by using the neighbor-joining method. Proc. Nat Acad Sci. US. A 101, 11030-11035.

van Niekerk, M., Freeman, M., Paweska, J.T., Howell, P.G., Guthrie, A.J., Potgieter, A.C., van Staden, V., Huismans, H., 2003. Variation in the NS3 gene and protein in South African isolates of bluetongue and equine encephalosis viruses. J. Gen. Virol. 84, 581-590. 